\title{
Effects of forced air precooling and MA film packaging on quality characteristics of 'Fuji' apples
}

\author{
Sang-Tai Hong ${ }^{1 *}$, Yang-Kyun Park ${ }^{2}$, Hyung-Woo Park ${ }^{3}$ \\ ${ }^{1}$ Department of International Logistics, Pyeongtaek University, Pyeongtaek 17869, Korea \\ ${ }^{2}$ Department of Food Engineering, Mokpo National University, Muan 58554, Korea \\ ${ }^{3}$ Food Processing Research Center, Korea Food Research Institute, Wanju 55365, Korea
}

\section{‘후지’ 사과의 품질에 대한 강제송풍 예냉처리와 MA 필름 포장의 효과}

\author{
홍상태 ${ }^{1 *} \cdot$ 박양균 $^{2} \cdot$ 박형우 $^{3}$ \\ ${ }^{1}$ 평택대학교 국제물류학과, ${ }^{2}$ 목포대학교 식품공학과, ${ }^{3}$ 한국식품연구원
}

\begin{abstract}
This study was carried out to find a method of pretreatment before storage to improve the shelf life of apples. Fuji apple was pretreated with forced air precooling and pretreated with neutral water and packed in a functional MA film and stored for 18 weeks at $0^{\circ} \mathrm{C}$ to investigate changes in quality such as weight, hardness, decay rate, titratable acidity and vitamin $\mathrm{C}$. The weight loss of apple packed functional MA film was higher than that of control, weight loss of control was $6.3 \%$ and that of functional MA films were $0.3-0.9 \%$. The change of hardness and titratable acidity was also lower than that of control. The decay ratio of apple packed with functional MA films were $1.7-1.4 \%$ but that of control was $5.3 \%$, the decay ratio of control was higher than those of functional MA film. Vitamin C also showed little change in MA film packaging after pretreatment. Therefore, when the apple is stored for a long period, it is effective to maintain quality of Fuji apple by forced air precooling method or precooling to low temperature with neutral water and storage in MA film packaging.
\end{abstract}

Key words : forced air precooling, MA, apple, quality characteristics

\section{서 론}

사과는 국내에서 많이 생산되는 과일 중의 하나로 2017 년 생산된 전체 과일류 2,275천 톤 중에서 사과는 365 천 톤으로(1) 약 $16 \%$ 를 차지하고 있다. 세계적으로 2015년에 생산된 사과는 58,782 천 톤으로 이중 중국에서 $35.9 \%$ 인 21,105 천 톤이 생산되었고, 그 다음으로 미국이 $6.6 \%$, 터키, 프랑스 등이 $4 \%$ 미만이었다(2). 사과의 수확 후 저장 유통 중 비상품과 비율이 $15 \%$ 를 상회하고 있고, 저장 중에 발생 하는 생리대사, 증산작용 등으로 사과의 중량 감소는 $13 \%$

*Corresponding author. E-mail : logis386@hanmail.net Phone : 82-10-5239-2653, Fax : 82-31-659-8530

Received 05 August 2019; Revised 14 September 2019; Accepted 19 September 2019.

Copyright (c) The Korean Society of Food Preservation. All rights reserved.
정도 된다. 수확 후 관리기술이 향상되면 부패율과 중량감 소를 줄일 수 있으며, 저장 중 선도유지로 인한 상품성 향상 효과도 거둘 수 있다. 수확 후 신선도 품질 유지 연구로는 예냉처리(3), 저온저장(4), MA(modified atmosphere) 포장 기술(5), 칼슘처리(6) 및 열수처리, 내부온습도나 공기조성 조절을 위한 포장재 적용(7)에 관한 연구 등이 있다. MA 포장방법은 과실의 생리대사로 인하여 발생되는 가스에 의해 포장재 내에 가스조성이 변하므로 생리대사가 진행됨 에 따라 가스농도가 지속적으로 조절된다. 그 외에도 항균, 고차단, 분해성, 원적외선 방사 등의 부가적인 기능을 부여 한 기능성 포장재의 효과가 연구되었다(8). Lau는 사과품종 별 $\mathrm{CO}_{2}$ 함량과 $\mathrm{O}_{2}$ 함량에 따라 저장특성에 미치는 영향을 조사한 바 있다(9). 또한 $\mathrm{Kitamura(10)이} \mathrm{사과저장} \mathrm{중} \mathrm{에틸}$ 렌 생산량에 관하여 조사한 결과, 초기 2주일 동안은 $4 \mathrm{ppm}$ 에 달했고 1개월마다 0.3-0.5 ppm씩 상승한다고 하였다. Knee와 Hatfield(11)는 저장고내에서 축적된 에틸렌을 제거 
함으로써 사과의 연화를 줄일 수 있다고 하였다. 사과의 수확 후 전처리 연구로는 박 등이 산 및 결로 방지 처리한 기능성 MA 포장한 사과의 신선도(12), 박 등이 산, 염기 처리된 제올라이트와 결로 방지제를 함유한 기능성 $\mathrm{MA}$ 포장재로 포장한 후지사과의 신선도(13) 등이 있으나 수확 후 사과의 호흡으로 인한 품온 상승을 억제하고자 저온으로 사과 품온을 낮추는 강제송풍방식에 의한 강제송풍 예냉 (14)과 살균기능과 세정작용이 있다고 보고된 중성수(15) 로 전처리하여 기능성 $\mathrm{MA}$ 필름에 포장한 연구는 보고된 것이 없다. 본 연구에서는 사과의 저장성을 향상시키기 위 해 사용되는 MA 포장에서 전처리로 강제송풍 예냉(14)과 고준위 환원 중성수 침지가 후지 사과의 저장성에 미치는 품질변화 영향을 비교 조사하였다.

\section{재료 및 방법}

\section{재 료}

사과는 경남 거창에서 생산한 '후지' 사과(Malus pumila) 를 구입하여 $230-250 \mathrm{~g}$ 크기, 색깔이 비슷하고 수확시기가 같은 것으로 선별하여 사용하였다.

\section{전처리 포장 및 저장 방법}

선별된 사과를 강제송풍 예냉(forced air precooling) 장치 (14)를 사용하여 사과 내부에 센서를 꼽아 사과 품온이 $4^{\circ} \mathrm{C}$ 로 떨어지도록 예냉 한 후 기능성 $\mathrm{MA}$ 필름으로 포장한 처리구(precooling modified atomosphere, PCMA)와 $\operatorname{Kim}(15)$ 의 방법으로 제조한 고준위 환원 중성수의 온도를 $5^{\circ} \mathrm{C}$ 되게 냉각한 후 중성수에 사과가 잠기도록 하여 30 분간 침지시켜 건조한 후 기능성 $\mathrm{MA}$ 필름으로 포장한 처리구 (neutral water modified atmosphere, NWMA)의 2 종의 전처 리구와 MA 필름으로 내포장을 하지 않는 것을 대조구 (control)로 하여 저장중 품질변화를 조사하였다. 기능성 필 름의 두께는 $0.03 \mathrm{~mm}$, 크기는 $90 \times 90 \mathrm{~cm}$ 인 MA포장재(16) 에 후지 사과 $15 \mathrm{~kg}$ 씩 포장하여 $0^{\circ} \mathrm{C}$ 에 18 주 저장하면서 시료로 사용하였다.

\section{물리적 변화}

중량 변화율은 포장 후 초기 값에 대한 중량에서 측정시 중량을 뺀 중량에 대한 백분율(\%)로 하였으며, 과육의 경도 는 시료를 중심에서 약 $1 \mathrm{~cm}$ 정도 위치를 종단면으로 절단한 후 Rheometer(CR-200D, SUN, Japan)를 사용하여 과핵 쪽으 로 probe를 $50 \mathrm{~mm} / \mathrm{min}$ 속도로 $10 \mathrm{~mm}$ 삽입할 때 나타나는 조직의 저항치를 hgf로 나타내었다. 부패율은 육안으로 보 아 식별이 가능한 것을 부패과로 인정하여 전체 조사한 사과에 대한 백분율로 하였다.

\section{화학적 성분의 변화}

처리구별로 시료 10 개를 개당 $1 / 8$ 조각씩 mixer(Osterizer, Philips, USA)로 마쇄, 여과하여 시료로 사용하였으며, 산도 는 $0.1 \mathrm{~N} \mathrm{NaOH}$ 로 $\mathrm{pH} 8.1$ 까지 적정하여 소비된 양을 malic acid로 환산하였다.

$$
\begin{aligned}
\text { 산도 }(\%) & =[0.1 \mathrm{~N} \quad \mathrm{NaOH} \quad \text { 소비량 }(\mathrm{mL}) \times \text { 산도계수 } \\
& (0.0067) \times 100] / \text { 시료 }(\mathrm{g})
\end{aligned}
$$

비타민 C 함량은 DNP 비색법으로 측정하였다. 일정량의 시료를 동량의 $5 \%$

metaphosphoric acid 용액과 혼합하여 여과 후 여과액을 $2 \mathrm{~mL}$ 씩 시험관 2 개에 취한 후 시험관 1 에 indophenol 용액을 첨가하고, 시험관 1,2 에 $5 \% \mathrm{HPO}_{3}$-thiourea 용액을 $2 \mathrm{~mL}$ 씩 가하여 시험관 1 은 총 vitamin $\mathrm{C}$, 시험관 2 는 blank로 하였다. 시험관 1, 2에 DNP 용액을 가하고 osaxone을 형성, 용해, 흡광도 측정의 순서로 조작하여 spectrophotometer(V-530, Jasco, Japan)을 이용하여 $540 \mathrm{~nm}$ 에서 흡광도를 측정하여 계산하였다.

\section{통계처리}

모든 실험은 3회 반복하여 측정하였으며 시험결과는 평 균값 \pm 표준편차로 나타내었다. 처리 평균 간의 유의성 검정 은 SAS(Statistical Analysis System, 8.1, SAS Institute Inc., Cary, NC, USA) program을 이용하여 $\mathrm{p}<0.05$ 수준에서 Duncan's multiple range test 방법을 사용하여 통계 처리하 였다.

\section{결과 및 고찰}

\section{중량 변화}

예냉 처리한 '후지' 사과의 저장기간에 따른 중량 감소율 의 변화는 Fig. 1 과 같다. $0^{\circ} \mathrm{C}$ 저장 18 주째에 대조구는 $6.3 \%$, 강제송풍 예냉 후 기능성 필름으로 포장한 처리구 (precooling modified atomosphere, PCMA)는 $0.3 \%$, 중성수 침지 후 기능성 필름으로 포장한 처리구(neutral water modified atmosphere, NWMA)는 $0.4 \%$ 의 중량이 감소되었 다. 현장 접목시험에서 기능성 필름포장구의 저온저장 18 주째 중량 감소율이 $0.9 \%$ 로 큰 차이가 나지 않았으며, 이는 $\mathrm{Kim}$ 등(7)의 연구결과에서도 LDPE 필름포장구와 예냉 후 $\mathrm{LDPE}$ 필름으로 포장한 경우 $4^{\circ} \mathrm{C}$ 에서 20 주 동안 저장했을 때 각각 $0.6,0.7 \%$ 의 중량이 감소되어 두 가지 전처리 방법 간의 중량변화는 유의적인 차이가 없었다는 보고와도 일치 하였다. 강제송풍 예냉 포장구(PCMA)와 중성수 처리한 포장구(NWMA) 두 전처리구 간에 중량변화 차이가 없었던 것은 중성수의 온도가 $5^{\circ} \mathrm{C}$ 되는 것에 30 분 간 침지함으로서 
예냉효과가 나타난 것으로서 판단되었다.

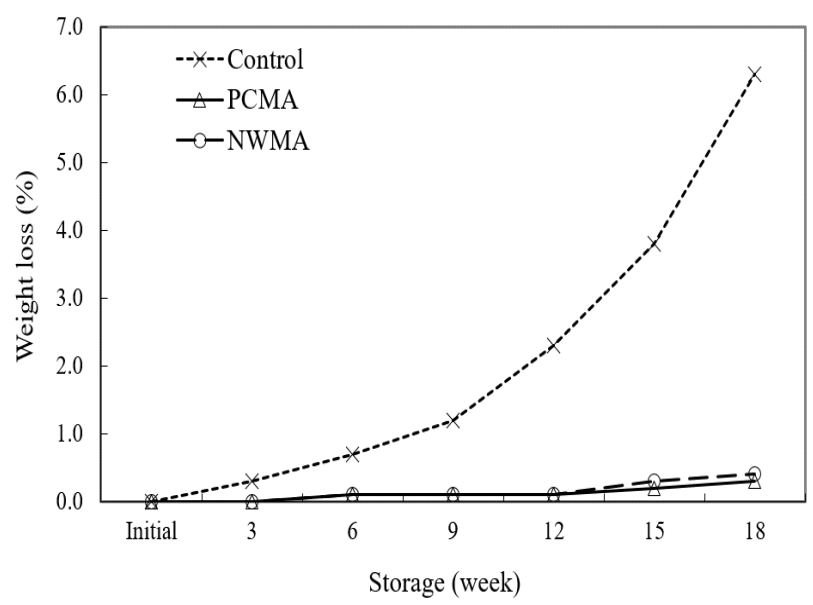

Fig. 1. Changes in weight loss of 'Fuji' apples by precooling treatments during storage at $0^{\circ} \mathrm{C}$.

PCMA: Precooling Modified Atmosphere, NWMA: Neutra Water Modified Atmosphere.

\section{경도 변화}

예냉 처리한 '후지' 사과의 $0^{\circ} \mathrm{C}$ 저장 기간에 따른 경도의 변화는 Fig. 2 와 같다. 저장기간의 경과에 따라 감소하는 경향을 보였으며, 저온저장 18 주째 대조구는 초기치 1.02 $\mathrm{kg}_{\mathrm{f}}$ 에서 $0.60 \mathrm{~kg}_{\mathrm{f}}$ 으로 $41 \%$ 감소하였으며, $\mathrm{PCMA}$ 구는 1.02 $\mathrm{kg}_{\mathrm{f}}$ 에서 $0.69 \mathrm{~kg}_{\mathrm{f}}$ 로 $32 \%, \mathrm{NWMA}$ 구는 $1.02 \mathrm{~kg}_{\mathrm{f}}$ 에서 $0.67 \mathrm{~kg}_{\mathrm{f}}$ 로 $34 \%$ 감소하였다. Park과 Ryu(12)의 연구에서도 사과를 산.염기 처리 후 기능성 $\mathrm{MA}$ 필름으로 포장하여 저장하였 을 경우 경도변화가 대조구보다 적었다고 한 보고와도 비슷 한 경향을 보였다. 현장 접목시험에서는 기능성 필름 포장 구의 경도 감소율이 $37 \%$ 로 칼슘 및 중성수 처리보다 다소 높게 나와 예냉처리가 사과의 경도 유지에 효과가 있는 결과이었다.

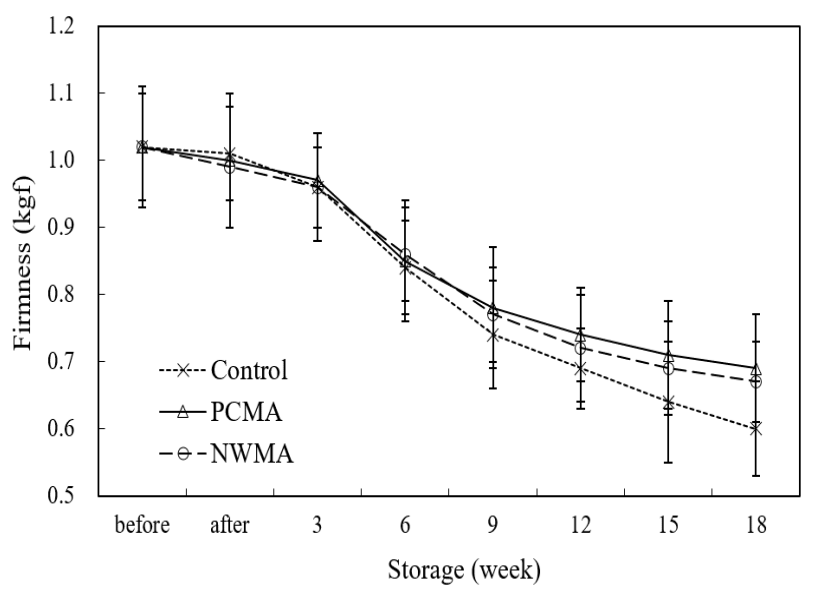

Fig. 2. Changes in firmness of 'Fuji' apples by precooling treatments during storage at $0^{\circ} \mathrm{C}$.

NT: Non Precooling Treatment. All values are expressed as mean $\pm S D(n=5)$. (Means separation within a column by Duncan's multiple range test $(\mathrm{p}=0.05)$.)

\section{부패율 변화}

예냉 전처리한 ‘후지' 사과의 $0^{\circ} \mathrm{C}$ 저장 기간에 따른 부패 율의 변화는 Fig. 3과 같다. 부패율은 저장기간이 경과될수 록 증가하였으며, 저온저장 18 주째 대조구는 $5.3 \%, \mathrm{PCMA}$ 구는 $1.7 \%, \mathrm{NWMA}$ 구는 $1.4 \%$ 이었다. Park과 $\mathrm{Ryu}(13)$ 의 연 구에서도 '후지' 사과를 산처리 후 LDPE 필름으로 포장하 여 $0^{\circ} \mathrm{C}$ 에서 6 개월 동안 저장한 결과 대조구는 $5.4 \%$, 산 처리한 후 기능성 $\mathrm{MA}$ 필름으로 포장한 사과는 $1.5 \%$ 의 부패 율을 보여 본 연구와 유사한 결과이었다.

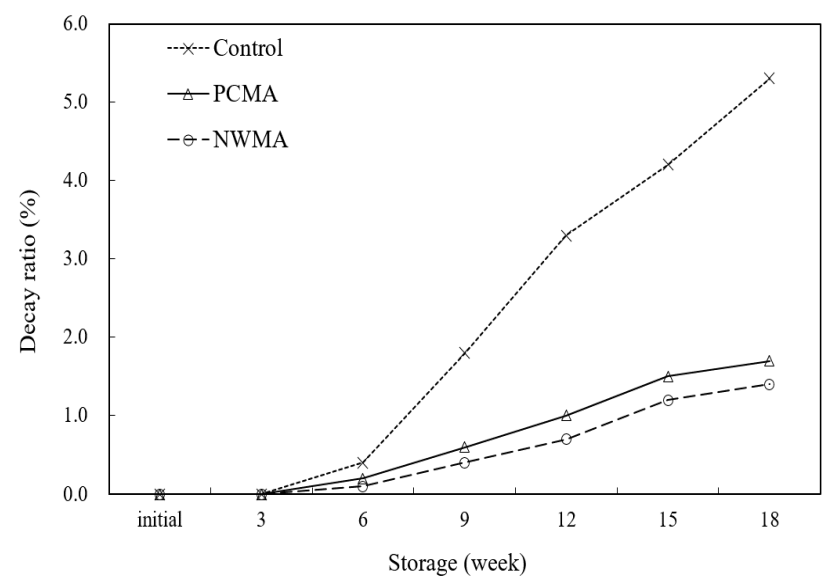

Fig. 3. Changes in decay ratio of 'Fuji' apples by precooling treatments during storage at $0^{\circ} \mathrm{C}$.

\section{적정산도 변화}

예냉 처리한 '후지' 사과의 $0^{\circ} \mathrm{C}$ 저장 기간에 따른 적정산 도의 변화는 Fig. 4 와 같다. 저장기간이 경과됨에 따라 감소 하는 경향을 보였으며, 저온저장 18 주째 대조구는 $0.08 \%$ 로 초기 값 $0.25 \%$ 에 비해 $67 \%$ 감소되었으며, 예냉 처리한

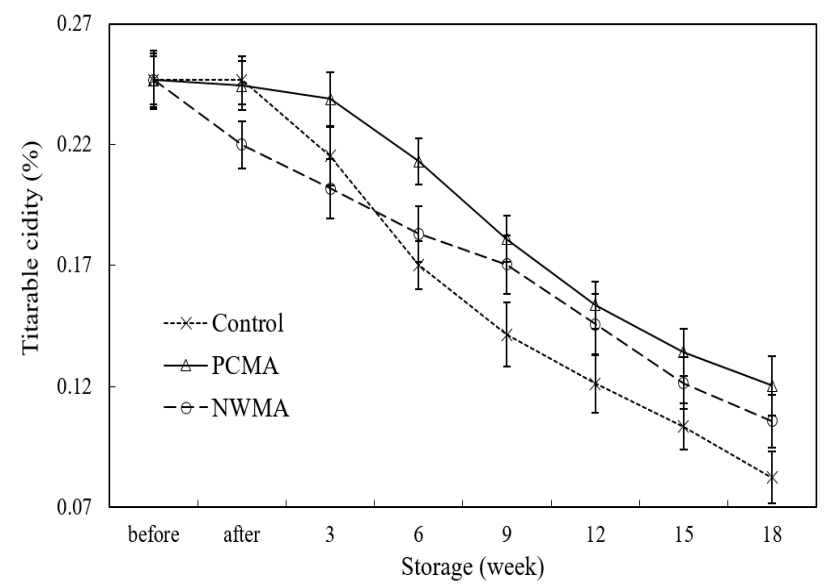

Fig. 4. Changes in titratable acidity of 'Fuji' apples by precooling treatments during storage at $0^{\circ} \mathrm{C}$.

NT: Non Precooling Treatment. All values are expressed as mean $\pm \mathrm{SD}(\mathrm{n}=5)$. (Means separation within a column by Duncan's multiple range test $(\mathrm{p}=0.05))$. 
$\mathrm{PCMA}$ 구는 $0.12 \%$ 로 $51 \%, \mathrm{NWMA}$ 구는 $0.11 \%$ 으로 $57 \%$ 감 소하여 예냉 처리구와 대조구간에 유의적인 차이를 보였으 며, 포장하기 전에 예냉과 중성수 등의 방법으로 전 처리하 는 것이 '후지' 사과의 산도유지에 더 효과적이라고 판단되 었다.

\section{비타민 C 변화}

예냉 처리한 후지 사과의 저장기간에 따른 비타민 $\mathrm{C}$ 의 변화는 Fig. 5 와 같다. 모든 시험구에서 저장기간이 경과됨 에 따라 대체로 감소하였으며, $0^{\circ} \mathrm{C}$ 저온 저장 18 주째 대조구 는 초기 값 $8.3 \mathrm{mg} \%$ 에서 $3.42 \mathrm{mg} \%$ 으로 $59 \%$ 감소되었으며, 강제송풍 예냉 처리한 $\mathrm{MA}$ 필름 포장구(PCMA)는 4.19 $\mathrm{mg} \%$ 로 $50 \%$ 감소, 중성수 처리한 $\mathrm{MA}$ 필름 포장구(NWMA) 는 $3.95 \mathrm{mg} \%$ 로 $53 \%$ 감소하였다. $\mathrm{Kim}$ 등(7)의 연구에서도 사과를 예냉처리 후 필름으로 포장하여 $4^{\circ} \mathrm{C}$ 에서 20 주 동안 저장한 결과 처리구가 대조구보다 $26 \%$ 높은 함량을 나타내 어 본 실험과 비슷한 경향이었다.

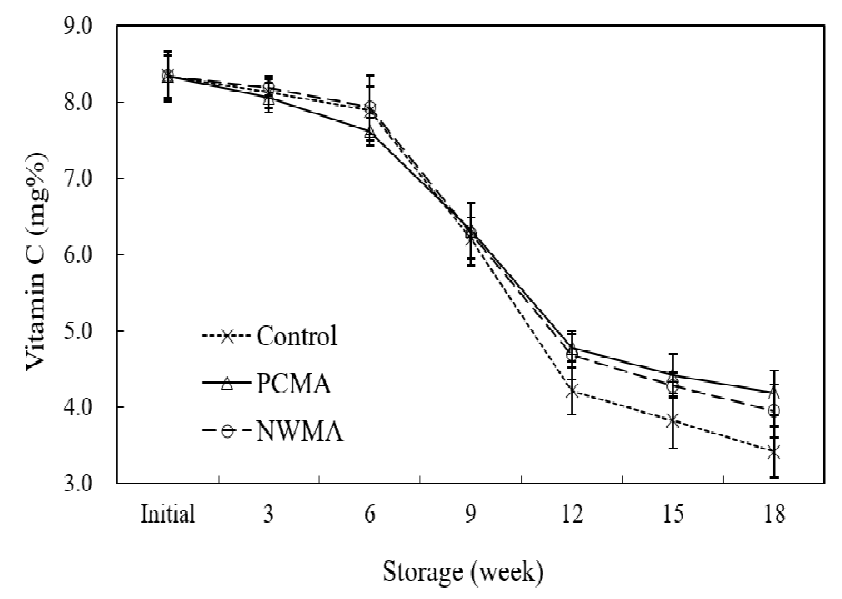

Fig. 5. Changes in vitamin C content of 'Fuji' apples by precooling treatments during storage at $0^{\circ} \mathrm{C}$.

All values are expressed as mean $\pm \mathrm{SD}(\mathrm{n}=5)$. (Means separation within a column by Duncan's multiple range test $(\mathrm{p}=0.05)$ ).

\section{요 약}

후지 사과를 강제송풍 예냉 처리한 것과 중성수로 전처 리한 것을 기능성 $\mathrm{MA}$ 필름으로 포장하여 $0^{\circ} \mathrm{C}$ 에 18 주 동안 저장하면서 사과의 중량, 경도, 부패율, 적정산도 및 비타민 $\mathrm{C}$ 등의 품질변화를 조사하였다. 저장 18 주 후 중량변화는 대조구는 $6.3 \%$ 이었으나 전처리 후 기능성 $\mathrm{MA}$ 필름에 포장 한 사과는 0.3-0.9\%이었다. 경도와 산도의 경우도 기능성 $\mathrm{MA}$ 필름 포장구에서 변화가 적었다. 부패율은 대조구는 $5.3 \%$, 기능성 $\mathrm{MA}$ 포장구는 $1.7-1.4 \%$ 로 전처리한 기능성 $\mathrm{MA}$ 포장구에서 변화가 적었다. 비타민 $\mathrm{C}$ 의 경우도 전처리 한 후 $\mathrm{MA}$ 필름 포장구에서 변화가 적은 것으로 나타나
사과를 장기 저장할 경우 강제송풍 방법이나 저온의 중성수 에 예냉 처리하여 $\mathrm{MA}$ 포장 저장하는 것이 후지 사과의 품질유지에 효과적이었다.

\section{References}

1. MAFRA (2018) Agriculture, Food and Rural Affairs Statistics Yearbook, Naju, Jeollanam-do, Korea

2. FAO (2017) Production of Fruits \& Vegetables, FAO Statistics, Rome, Italy

3. Echeverria G, Fuentes T, Graell J, Lara I, Lopez ML (2004) Aroma volatile compounds of 'fuji' apples in relation to harvest date and cold storage technology. A comparison of two seasons. Postharvest Biol Technol, 32, 29-44

4. Parvathy S, Abdullah H, Latifah MN, Tarmiz S (2003) Effect of packaging system on the quality of wax apple (Eugenia javanica syn. Samarangense) stored at low temperature. J Food Sci Technol, 40, 177-182

5. Mostofi Y, Hajizadeh HS, Talaie A, Mousavi EZ (2008) Modified atmosphere packaging (MAP) effects on quality maintenance and storage life extension of local Iranian apple 'Olab Kohanz'. Acta Hort, 768, 103-109

6. Chung HS, Chol JU (1999) Suitability judgment of storage conditions by internal gas concentration of 'fuji' apples under CA storage. Korean J Food Sci Technol, 31, 1295-1299

7. Kim BS, Hyun NU, Nahmgoong B (1999) Effect of pressure cooling for quality of 'sugaru' apple during storage at different temperatures. Korean J Postharvest Sci Technol, 6, 371-375

8. Chung DS, Lee YS (2009) Applications of functional tray form packaging to extend the freshness of high quality 'Fuji' apples. Korean J Food Preserv, 16, 817-823

9. Lau LO (1983) Effects of storage procedures and low oxygen and carbon dioxide atmospheres on storage quality of Spartan apples. J Amer Soc Hort Sci, 108, 955-959

10. Kitamura T, Iwata T, Ochiai T, Fukushima T (1980) The changes in respiration, ethylene examination and internal ethylene concentration and the several maturation criteria with reference to apple cultivars. J Japan Soc Hort Sci, 49, 227-229

11. Knee M, Hatfield SGS (1981) Benefits of ethylene removal during apple storage. Ann Appl Biol, 98, 157-161 
12. Park HW, Ryu NH (2013) Effect of chemical and anti-fogging agent treated MA packaging film on freshness extension of 'Fuji' apples. Korean J Packaging Sci Technol, 19, 87-94

13. Park HW, Ryu NH (2013) Freshness of 'Fuji' apples packed MA film treated with acid and anti-fogging agents. Korean J Packaging Sci Technol, 19, 43-50

14. Kim OW, Kim H, Han JW, Lee Hj (2013) An air flow resistance model for a pressure cooling system based on container stacking methods. Korean J Food Preserv, 20, 289-295
15. Kim YH (2012) High energy physics ruduced neutral water producing method. Korea patent No. 10-1168134

16. Park HW (1994) Studies on the development of modified atmosphere packaging films for fruits and vegetables. $\mathrm{Ph}$ D Thesis, Korea University, Korea 